\title{
Inhibition of endothelin A receptor protects brain microvascular endothelial cells against hypoxia-induced injury
}

\author{
XI LIU, FEN DENG, ZHEN YU, YUNLAN XIE, CHANGLIN HU and LIFEN CHEN \\ Department of Neurology, the Second Affiliated Hospital of Chongqing Medical University, Chongqing, P.R. China
}

Received December 22, 2013; Accepted April 9, 2014

DOI: $10.3892 /$ ijmm.2014.1744

\begin{abstract}
Endothelin-1 (ET-1)-induced cell damage is commonly involved in ischemia/hypoxia-associated diseases. PD155080 [sodium 2-benzo (1.3)dioxol-5-yl-3-benzyl-4(4-methoxyphenyl)-4-oxobut-2-enoate] is a selective endothelin A receptor (ETAR) antagonist that inhibits ET-1-induced cell damage. The aim of this study was to investigate the effects of PD155080 on hypoxia-induced rat brain microvascular endothelial cell (BMEC) injury. BMECs were isolated from the cerebral cortex of Wistar rats and cultured in an anoxia chamber, containing 95\% $\mathrm{N}_{2}$ and $5 \% \mathrm{CO}_{2}$ for $12 \mathrm{~h}$. BMEC injury was assessed by determining cellular ultramicrostructural changes and cell viability by MTT assay, trypan blue (TB) staining and measuring the lactate dehydrogenase (LDH) levels. ET-1 mRNA expression was detected by in situ hybridization and reverse transcription PCR (RT-PCR); the ET-1 protein level was measured by radioimmunoassay. Following exposure to hypoxic conditions, the viability of the BMECs was markedly decreased and the ultrastructure of the BMECs was damaged, as demonstrated by chromatin margination, chromatin agglutination, plasma edema, the increased number of intracellular liposomes and vacuoles, mitochondrial swelling and the expansion of a rough surfaced endoplasmic reticulum. The levels of ET-1 and ET-1 mRNA expression in the BMECs were increased following exposure to hypoxic conditions. Of note, the administration of PD155080 greatly enhanced the viability of the BMECs and ameliorated hypoxia-induced cellular injury. PD155080 also inhibited hypoxia-induced ET-1 production by the BMECs. In conclusion, PD155080 exerts protective effects against hypoxia-induced BMEC injury.
\end{abstract}

\section{Introduction}

Hypoxia is common in cerebral vascular diseases and leads to brain damage. Endothelial cells are particularly vulner-

Correspondence to: Dr Lifen Chen, Department of Neurology, the Second Affiliated Hospital of Chongqing Medical University, 74 Linjiang Road, Yuzhong, Chongqing 400010, P.R. China

E-mail: lifen_chen@163.com

Key words: brain microvascular endothelial cell, hypoxia, PD155080, endothelin-1 able to hypoxia-induced damage (1). Hypoxia has been reported to inhibit vessel formation (2), resulting in a series of pathophysiological changes in brain endothelial cells (3). Endothelin-1 (ET-1) is a potent vasoconstrictor released by endothelial cells. ET-1 functions as a paracrine regulator of vascular tone, and exerts deleterious effects on water homeostasis, cerebral edema and brain blood barrier (BBB) integrity. All these factors further contribute to severe ischemic brain injury (4). The increase in ET-1 secretion by endothelial cells is one of the major pathological changes induced by hypoxia (3). A previous study on brain endothelial cells revealed that, within 0.5 to $2 \mathrm{~h}$ of hypoxia, the mRNA level of ET-1 was elevated (2). In addition, physiologically low oxygen tension has been shown to increase endothelin secretion from cultured human endothelial cells (5). As ET-1 functions by activating the endothelin A receptor (ETAR) (6), antagonists of ET-1 receptors may serve as good candidates for the treatment of cerebral ischemia (7). PD155080 is a selective ETAR antagonist. It has been reported to be effective in limiting tissue damage induced by ET-1 in animal models of pathological vasospasm and therefore, it may be beneficial for clinical use in ET-implicated diseases (8). However, the protective effects of PD155080 in in vitro models, such as cultured endothelial cells, remain largely unknown. Since the in vitro culture of cerebral microvascular endothelial cells is important in the research of cerebral vascular disease, particularly cerebral ischemia/hypoxia-related diseases $(9,10)$, in the present study, we investigated the protective effects of PD155080 against hypoxia-induced rat brain microvascular endothelial cell (BMEC) injury in vitro.

\section{Materials and methods}

Isolation of BMECs. This study was approved by the Ethics Committee of the 2nd Affiliated Hospital of Chongqing Medical University. The BMECs were isolated from the cerebral cortex of Wistar rats and cultured according to a previous report (11). Briefly, brain tissue was collected from newborn (1-5 days old) Wistar rats, provided by the Experimental Animal Center of Chongqing Medical University, Chongqing, China. Following the removal of major vessels, cerebral pia mater, brain stem and medullary substances, the tissue samples were homogenized. The homogenate was filtered through a nylon membrane $(75 \mu \mathrm{m}$ aperture). The filter residue was flushed with cold Hank's solution, and was centrifuged at $500 \mathrm{rpm}$ for $3 \mathrm{~min}$ to collect the microvascular fragments. The collections were dissoci- 
ated with $0.1 \%$ collagenase VII (Sigma-Aldrich Co., LLC, St. Louis, MO, USA) at $37^{\circ} \mathrm{C}$ for $20 \mathrm{~min}$, and centrifuged again at $800 \mathrm{rpm}$ for $3 \mathrm{~min}$. The liquid supernatant was discarded and the cell pellet was resuspended in M199 complete culture medium (HyClone Laboratories, Inc., Logan, UT, USA), which contained $15 \%$ fetal bovine serum. The cells were cultured in 35-ml plastic flasks, which were placed upside down immediately after cell implantation, and incubated at $37^{\circ} \mathrm{C}, 5 \% \mathrm{CO}_{2}$ for $2 \mathrm{~h}$. The plastic flasks were then turned upward. The medium was replaced 1 day after the cells were plated, and again after 3 days and, thereafter, until the cells became unified and formed a monostratal layer. During the first 2-5 days of culture, the cultured cells were observed under an inverted microscope once a day,. All the cells or cell clusters that were not typically triangular or shuttle-shaped with pale nuclei and a distinct cytomembrane were suspected as contaminated cells and were eliminated using a cell scrapper. The cells were dissociated with $0.25 \%$ parenzyme (Sigma-Aldrich Co., LLC) for passage cultures, and the third generation of cultured cells was used in the experiments in this study.

Establishment of a hypoxic BMEC model in vitro. The cultured BMECs were placed in a hypoxic, hermetic container with $95 \% \mathrm{~N}_{2}$ and $5 \% \mathrm{CO}_{2}$ (Chongqing Air Liquefaction Corporation, Ltd., Chongqing, China) and were cultured at $37^{\circ} \mathrm{C}$ for $12 \mathrm{~h}$.

Experimental groups. The BMECs were divided into the normal controls, hypoxia and PD155080 groups. In the normal controls, the BMECs were conventionally cultured without any stimulatory factors. In the hypoxia group, the BMECs were cultured inside a container with $95 \% \mathrm{~N}_{2}$ and $5 \% \mathrm{CO}_{2}$ for $12 \mathrm{~h}$. In the PD155080 group, the BMECs were first treated with PD155080 $(1 \mu \mathrm{M})$ (Pfizer Pharmaceutical Co, Ltd., New York, NY, USA) for $2 \mathrm{~h}$, and were then cultured in the same hypoxic environment as the hypoxia group for $12 \mathrm{~h}$ in the presence of PD155080.

\section{Detection of biomarkers}

Identification of BMECs and their ultrastructures. In this study, the morphology of the endothelial cells was observed using an inverted microscope, a transmission electronic microscope and by immunocytochemical staining for factor VIII-related antigen (Beijing Zhongshan Golden Bridge Biotechnology Co., Ltd., Beijing, China). To assess the ultrastructure of the cells, the BMECs were conventionally prepared for electron microscopic observation following fixation with $2 \%$ glutaric dialdehyde solution, and the changes to the BMEC ultrastructure were observed using a transmission electronic microscope.

Measurement of cell viability by methyl thiazolyl tetrazolium (MTT) assay. A total of $200 \mu \mathrm{l}$ BMECs were plated in a 96-well culture plate at a density of $3 \times 10^{4} \cdot \mathrm{ml}^{-1}$, and were cultured for the indicated periods of time. At the end of the experiments, the culture medium was discarded and $200 \mu \mathrm{l}$ M199 + $20 \mu \mathrm{l}$ of $5 \mathrm{mg} / \mathrm{ml}$ MTT (Sigma-Aldrich Co., LLC) were added to each well. The cells were then cultured for a further $4 \mathrm{~h}$ and centrifuged at 2,000 $\mathrm{rmp}$ for $5 \mathrm{~min}$. The supernatant was discarded and $200 \mu 1$ dimethyl sulfoxide were added to each well. The absorbance (A) in each well was measured with an automatic enzyme-labeled instrument at a wavelength of $570 \mathrm{~nm}$.
Calculation of the mortality rate (\%) of BMECs with trypan blue (TB) staining. The BMEC suspension of each group was stained with TB (0.4\%), and 200 BMECs from each group (stained and unstained), were counted on blood cell counting plates under a light microscope. Mortality rate was calculated as follows: mortality $=($ number of dead BMECs $/ 200) \times 100 \%$.

Measurement of lactate dehydrogenase ( $L D H)$ activity. A total of $100 \mu \mathrm{l}$ of liquid supernatant from each group was collected at the indicated time points for each experiment. The LDH activity was measured using an LDH kit (Nanjing Jiancheng Bioengineering Institute, Nanjing, China) according to the manufacturer's instructions.

Determination of ET-1 concentration. The BMECs were plated in a 24-well plate at a density of $3 \times 10^{4} \cdot \mathrm{ml}^{-1}(\mathrm{n}=6$ per group). At the end of each experiment, $100 \mu \mathrm{l}$ of liquid supernatant from each group were collected to determine the concentration of ET-1 according to the instructions provided with the ET-1 radioimmunity kit (Dongya Immuno-technology Institute, Beijing, China).

Determination of ET-1 mRNA expression by in situ hybridization. An ET-1 in situ hybridization kit was purchased from Wuhan Boster Bio-Engineering Ltd., Co. (Wuhan, China). Digoxin-labeled oligonucleotides were used as the probe. The probe sequences were as follows: 5'-GATTATTTGCCCATG ATCTTCTCTCTGCTGTTCGT-3' and 5'-CCACCTGGACAT CATCTGGGTCAACACTCCCGAGC-3'. The cells were cultured on coverslips in 24-well plates. At the end of each experiment, the cells were fixed with $4 \%$ paraformaldehyde and washed with PBS. The cells were then immersed in pre-hybridization buffer at $37^{\circ} \mathrm{C}$ for $2 \mathrm{~h}$, followed by incubation in ET-1 oligonucleotide probe hybridization buffer at $43^{\circ} \mathrm{C}$ for $30 \mathrm{~h}$ and $1: 400$ anti-digoxin antibody at $37^{\circ} \mathrm{C}$ for $4 \mathrm{~h}$. Finally, the treated cells were measured using a 5-bromo-4-chloro3-indolyl-phosphate/nitro blue tetrazolium (BCIP/NBT) color-appearing system, using a hybridization buffer without a probe as the negative control. The results of in situ hybridization were analyzed using an image analysis system (Beihang CM2000B; Beihang University, Beijing, China) by measuring the absorbance (A) of each visual field under a microscope.

Determination of ET-1 mRNA expression by reverse transcription PCR (RT-PCR): a) the extraction of total RNA from $B M E C s$. Total RNA from the BMECs in each experimental group was extracted using TRIzol reagent (Sangon Biotech Co., Ltd., Shanghai, China) according to the manufacturer's instructions. RNA was dissolved with DEPC (Sigma-Aldrich Co. LLC) deionized water. The amount and purity of the RNA in each tube were measured using a UV-VIS spectrophotometer (Shanghai Precision Scientific Instrument Co., Ltd, Shanghai, China), and the samples with an optical density (OD) of $\geq 1.6$ were reverse transcribed.

b) cDNA synthesis. cDNA was synthesized using the M-MuLV First-Strand cDNA Synthesis kit (Sangon Biotech Co., Ltd.). Briefly, $2 \mu \mathrm{l}$ total RNA (1 $\mu \mathrm{g} / \mu \mathrm{l})$ from each group was mixed with $8 \mu \mathrm{l}$ DEPC deionized water and $1 \mu 1$ random hexamer primer $(0.2 \mu \mathrm{g} / \mu \mathrm{l})$, and then vortexed for $5 \mathrm{sec}$ and incubated at $70^{\circ} \mathrm{C}$ for $5 \mathrm{~min}$. Following incubation, the mixture was immersed in an ice-bath for $30 \mathrm{sec}$ and vortexed again for $5 \mathrm{sec}$. Subsequently, $4 \mu 15 \mathrm{X}$ reverse transcription buffer, $1 \mu 1$ RNAase inhibitor $(20 \mathrm{U} / \mu \mathrm{l})$ and $2 \mu 1$ deoxy-ribonucleoside triphosphate $(10 \mathrm{mM})$ were mixed with the RNA, and 


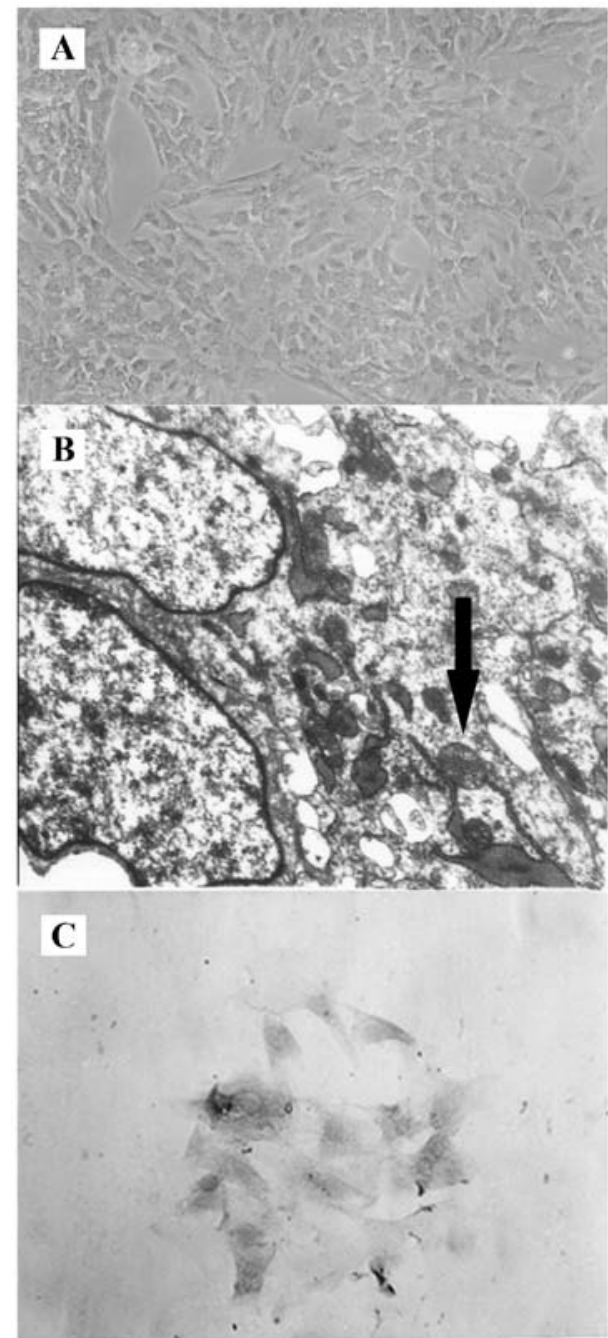

Figure 1. Identification of brain microvascular endothelial cells (BMECs) under an inverted microscope, transmission electron microscope and immunocytochemical staining for factor VIII-related antigen. (A) The endothelial cells were flaky, aggregated and closely arranged, and presented a typical pavestone-like structure under the inverted microscope (magnification, x100). (B) Typical claviform Weibel-Palada bodies (as indicated by the arrow) were observed in the cytoplasm under a transmission electron microscope (magnification, $\mathrm{x} 12,000$ ). (C) The cytoplasm and the area around the nuclear membrane of primary and third generation of cells were stained fuscous in immunocytochemical staining for factor VIII-related antigen under a light microscope (magnification, $\mathrm{x} 200$ ).

the mixture was incubated at $70^{\circ} \mathrm{C}$ for $5 \mathrm{~min}$. Subsequently, $1 \mu \mathrm{l}$ M-MuLV reverse transcriptase $(200 \mathrm{U} / \mu \mathrm{l})$ was added followed by sequential treatment in a water bath at $25^{\circ} \mathrm{C}$ for $10 \mathrm{~min}, 37^{\circ} \mathrm{C}$ for $60 \mathrm{~min}$ and $70^{\circ} \mathrm{C}$ for $10 \mathrm{~min}$; the mixture was then cooled on ice.

c) PCR reaction. PCR reactions were performed using the Gene/PCR System 2400 (PerkinElmer, Inc., Waltham, MA, USA). The sequences of ET-1 were as follows: sense primer, 5'-CGTTGCTCCTGCTCCTCCTTGATGG-3' and antisense primer, 5'-AAGATCCCAGCCAGCATGGAGAGCG-3'. Following initial denaturation at $94^{\circ} \mathrm{C}$ for $5 \mathrm{~min}$, an additional denaturation, annealing and elongation were performed at $94^{\circ} \mathrm{C}$ for $1 \mathrm{~min}, 60^{\circ} \mathrm{C}$ for $1 \mathrm{~min}$ and $72^{\circ} \mathrm{C}$ for $2.5 \mathrm{~min}$ for 35 cycles; the final elongation was performed at $72^{\circ} \mathrm{C}$ for $7 \mathrm{~min}$.

d) Identification and measurement of the ET-1 $\mathrm{mRNA}$ expression level. The mixture of $4 \mu \mathrm{l}$ amplification product and $2 \mu \mathrm{l}$ of sample loading buffer (6X) was loaded on a $1.5 \%$ agarose gel, which was run with a $0.5 \mathrm{X}$ TBE electrophoresis buffer (the buffers and the gel were produced by Sangon Biotech Co., Ltd). The gel was analyzed using an ultraviolet image analysis system (Gucun Electrical and Optical Instrument Factory, Shanghai, China), and the integral OD was measured using $\beta$-actin mRNA as an internal control. The ET-1 mRNA expression level was expressed as the ratio of the OD of the samples to $\beta$-actin.

Statistical analysis. The experimental results were analyzed using SPSS software, and are expressed as the means \pm standard deviation (means $\pm \mathrm{SD}$ ). Analysis of variance was used for comparisons between the groups, and the differences between groups were considered significant at $\mathrm{P}<0.05$. All figures were created using GraphPad Prism 6.01 sorftware (GraphPad Software, Inc., La Jolla, CA, USA).

\section{Results}

Identification of BMECs. To identify the characteristics of the isolated BMECs, observations were made under inverted and transmission electron microscopes. Under the inverted microscope, the endothelial cells were flaky, aggregated and closely arranged, and presented a typical pavestone-like structure (Fig. 1A). Typical claviform Weibel-Palada bodies were detected in the cytoplasm under the transmission electron microscope (Fig. 1B). We also performed immunocytochemical staining for factor VIII-related antigen, a marker for endothelial cells. As shown in Fig. 1C, the cytoplasm and the areas around the nuclear membrane were stained fuscous in endothelial cells of both primary and third generations, and $>95 \%$ of the third generation cells were positive for factor VIII-related antigen. These results suggested that the isolated cells were vascular endothelial cells.

Ultrastructural changes of BMECs cultured under hypoxic conditions. In order to observe the changes in the ultrastructure of the BMECs cultured under different experimental conditions, a transmission electron microscope was employed. The normal BMECs (conveniontally cultured) had an oblong-oval shape, as observed under an electron microscope, and were characterized by dense endonuclear chromatin, typical Golgi apparatus, endoplasmic reticulum and mitochondria, a high numer of perinuclear plasma, a complete plasma membrane and a nuclear membrane (Fig. 2A). However, the BMECs cultured under hypoxic conditions for $12 \mathrm{~h}$ were characterized by chromatin margination, chromatin agglutination, plasma edema, an increased number of intracellular liposomes and vacuoles, mitochondrial swelling and the expansion of a rough surfaced endoplasmic reticulum (Fig. 2B). Of note, the BMECs cultured under hypoxic conditions with PD155080 showed only mild mitochondrial swelling and the expansion of a rough surfaced endoplasmic reticulum (Fig. 2C), suggesting that PD155080 alleviated hypoxia-induced ultrastructural BMEC injury.

Effects of PD155080 on the viability and mortality of BMECs. To assess the effects of PD155080 on BMEC viability and mortality, we calculated the viability and mortality of BMECs in the 3 experimental groups. Compared to the normal controls 


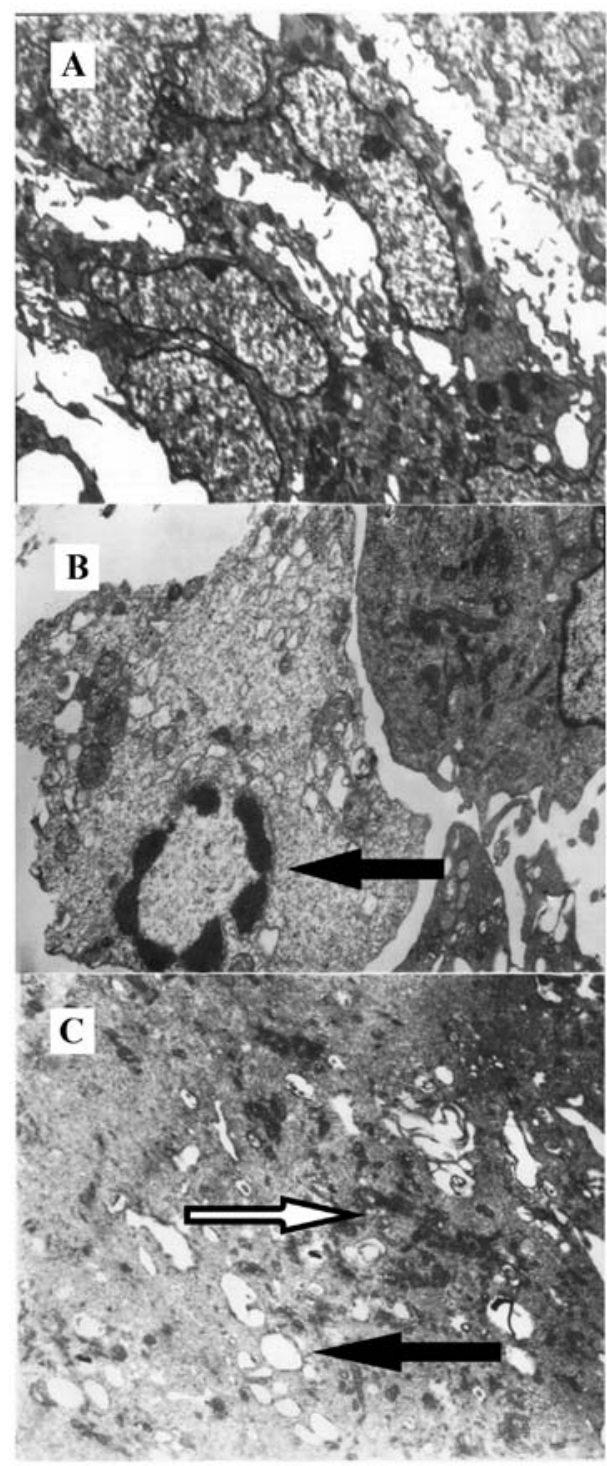

Figure 2. Ultrastructure of brain microvascular endothelial cells (BMECs) in the 3 groups. (A) Normal controls: BMECs presented dense intranulear chromatin and typical Golgi apparatus, endoplasmic reticulum and mitochondria (magnification, x5,000). (B) Hypoxic group: necrotic BMECs with nuclear margination (indicated by the arrow) and plasma edema (magnification, $\mathrm{x} 8,000$ ). (C) PD155080 group: BMECs with mild mitochondrial swelling (indicated by the black arrow) and expansion of a rough surfaced endoplasmic reticulum (indicated by the white arrow; magnification, $\mathrm{x} 8,000$ ).

(viability, $0.61 \pm 0.09$; mortality, $5.5 \pm 1.05$ ), the cerebral microvascular endothelial cells in the hypoxic group (viability, $0.33 \pm 0.07$; mortality, 41.17 \pm 8.01 ) showed a significantly decreased viability and an increased mortality $(\mathrm{p}<0.01)$. In the presence of PD155080, the cell viability was significantly increased and the mortality significantly decreased (viability, $0.47 \pm 0.06$; mortality, $19.50 \pm 4.59)$ compared to the hypoxic group $(\mathrm{p}<0.01)$ (Figs. 3 and 4). These results suggested that PD155080 inhibited hypoxia-induced damage to BMECs, and protected the BMECs from hypoxia-induced cell death.

Effects of PD155080 on LDH release. In order to determine to what extent PD155080 protects BMECs from hypoxia, we measured the release of LDH from the BMECs. A significant increase in the release of LDH was detected in the BMECs

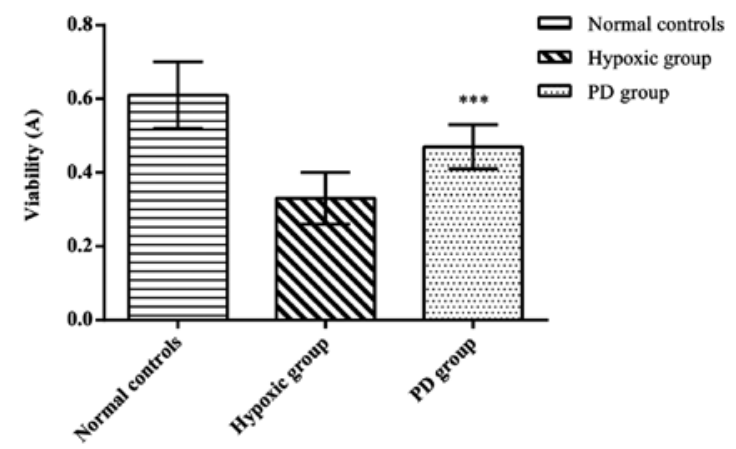

Figure 3. Effects of PD155080 (PD) on the viability of brain microvascular endothelial cells (BMECs). The viability of BMECs was calculated as the mean $\pm \mathrm{SD},{ }^{\mathrm{s}} \mathrm{P}<0.01$ vs. hypoxic group; $\mathrm{n}=9$ per group and the data are the average from 3 individual experiments.

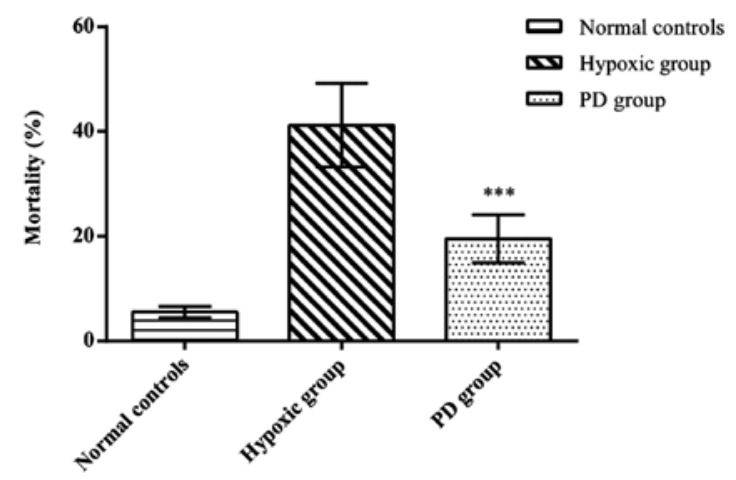

Figure 4. Eeffect of PD155080 (PD) on the mortality of brain microvascular endothelial cells (BMECs). The mean mortality rate of the BMECs was calculated as the mean $\pm \mathrm{SD},{ }^{* * *} \mathrm{P}<0.01$ vs. hypoxic group; $\mathrm{n}=6$ per group, and the data shown are the average of 2 individual experiments.

from the hypoxic group (LDH concentration, 1,667.33 \pm 244.31 ) compared with the normal controls (LDH concentration, 191.71 \pm 34.26$)(\mathrm{p}<0.01)$, whereas the release of LDH in the PD155080 group (LDH concentration, 837.50 \pm 130.16 ) showed a marked reduction compared to the hypoxic group $(\mathrm{p}<0.05)$ (Fig. 5). These results further demonstrated that treatment with PD155080 reversed the hypoxia-induced cellular damage.

Effects of PD155080 on the secretion of ET-1 by BMECs. To clarify the effects of PD155080 on ET-1 secretion by BMECs, we measured the ET-1 levels in the BMECs. We found that hypoxia increased ET-1 secretion from the BMECs compared with the control group $(\mathrm{p}<0.01)$, whereas the administration of PD155080 significantly reduced hypoxia-induced ET-1 secretion from the BMECs compared to those in the hypoxic group ( $\mathrm{p}<0.01$ ) (normal controls, $160.19 \pm 32.34$; hypoxic group, 426.13 \pm 64.80 ; PD155080 group, $266.40 \pm 50.45$; $\mathrm{p}<0.01$ ) (Fig. 6).

Effects of PD155080 on the ET-1 mRNA level in BMECs. To further determine the effects of PD155080 on hypoxia-induced ET-1 gene expression in the BMECs, we measured the ET-1 mRNA expression in the BMECs by in situ hybridization and RT-PCR. In the image analysis of in situ hybridization, 


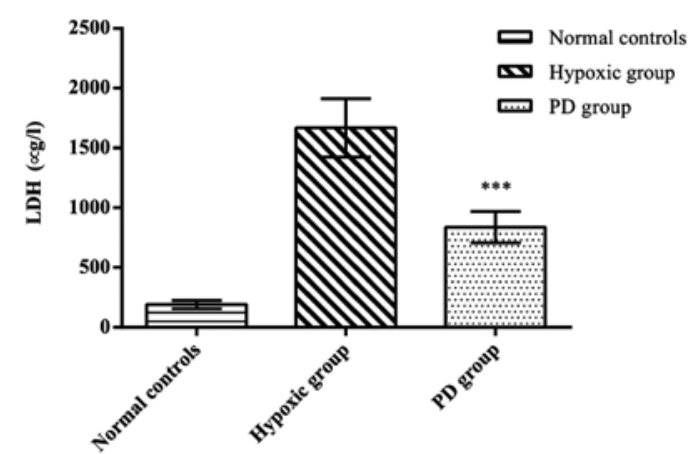

Figure 5. Effect of PD155080 (PD) on release of lactate dehydrogenase (LDH) by brain microvascular endothelial cells (BMECs). Release LDH by each group of cells was calculated as the mean $\pm \mathrm{SD},{ }^{* * *} \mathrm{P}<0.01$ vs. hypoxic group; $\mathrm{n}=6$ oer group and the data shown are the average of 2 individual experiments.

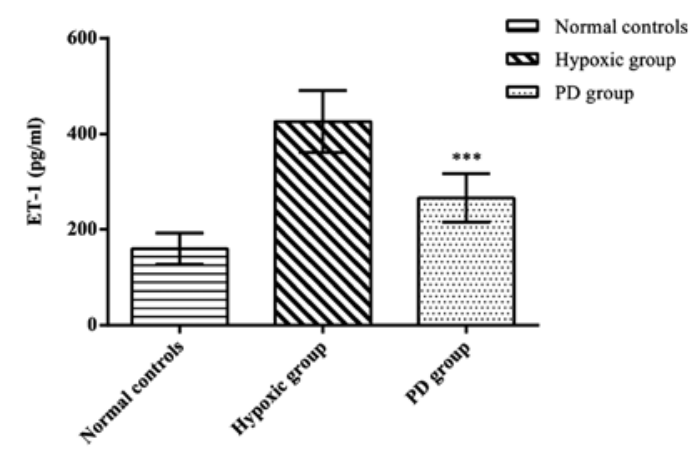

Figure 6. Effect of PD155080 (PD) on the secretion of endothelin-1 (ET-1) by brain microvascular endothelial cells (BMECs). ET-1 secretion was calculated as the mean $\pm \mathrm{SD},{ }^{* * * *} \mathrm{P}<0.01$ vs. hypoxic group; $\mathrm{n}=6$ per group; the data shown are the average of 2 individual experiments. the ET-1 mRNA level was significantly higher in the hypoxic group compared with the normal controls $(\mathrm{p}<0.01)$ (Fig. 7). However, treatment with PD155080 reduced the increased ET-1 mRNA expression induced by hypoxia $(\mathrm{p}<0.01)$ (normal controls, 0.06 \pm 0.02 ; hypoxic group, $0.21 \pm 0.04$; PD155080 group, $0.14 \pm 0.02$ ) (Fig. 7). Using RT-PCR, we also observed that the ET-1 mRNA level was significantly higher in the hypoxic group compared to the normal controls $(\mathrm{p}<0.01)$ (Fig. 8). PD155080 administration also reduced the hypoxia-induced ET-1 mRNA expression ( $\mathrm{p}<0.05$ ) (normal controls, $1.39 \pm 0.11$; hypoxic group, 1.92 \pm 0.10 ; PD155080 group, 1.71 \pm 0.17 ) (Fig. 8).

\section{Discussion}

Ischemic stroke is one of the major causes of disability and death; however, the therapeutic strategies for ischemic stroke are limited. Cerebral vascular endothelial cells, which regulate the vasomotion and metabolism of cerebral vessels by releasing a series of vasoactive substances, play an important role in the structural and functional abnormality of vessels in cerebral vascular diseases. It has been reported that artery segments with an intact endothelium show vasodilation during pressure decrease and vasoconstriction during pressure increase, while artery segments without an intact endothelium do not respond to pressure changes (12). In the present study, we investigated the effects of PD155080 on hypoxia-induced brain microvascular endothelial cell injury using an in vitro rat BMEC model. Our results demonstrated that hypoxia leads to the ultrastructural impairment of BMECs, characterized by pyknosis, condensation of nuclear chromatin, edema and vacuolization of the cells. Importantly, following pre-treatment of the BMECs with PD155080, the ultrastructure of the BMECs only showed mild mitochondrial swelling and the expansion of a rough surfaced endoplasmic reticulum following exposure to hypoxia. Compared with the hypoxic group, the viability of the BMECs in the PD155080 group was significantly higher and the mortality rate was reduced. The release of $\mathrm{LDH}$, which is in proportion to the membrane permeability changes, is a sensitive and convenient marker for cell injury and death (13). In our study, we found that the LDH level in the PD155080 group was lower compared to the hypoxic group. These results suggested that the inhibition of the ETA receptor using PD155080 increased the survival rate and reduced the release of LDH from the BMECs; therefore, PD155080 protects the BMECs from hypoxia-induced injury and may have a membrane-stabilizing effect on these cells. As previously demonstrated, PD155080 dilates vessels in ischemic stroke. An experiment on feline pial arterioles showed that the perivascular microapplication of PD155080 $(30 \mu \mathrm{M})$ around pial vessels within the territory of occluded middle cerebral artery elicited an increase in the caliber of both dilated and constricted pial arterioles following middle cerebral artery occlusion (MCAO) (14). A similar effect of PD155080 has also been reported in studies on coronary arteries using isolated perfused rat hearts, in which the addition of PD155080 resulted in a significant increase in the recovery of coronary flow after 30 min of reperfusion (15). More importantly, it has also been reported that 'increasing concentrations of PD155080 caused a progressive, parallel rightward shift of ET-1 concentrationresponse curve without detrimental effect on the maximal response to ET-1' (8).

One of the most important vasoactive substances released by cerebral endothelial cells is ET-1, the most powerful vasoconstrictor involved in the regulation of cerebral capillary microcirculation and vascular remodeling. The overproduction of ET-1 is related to the damage of cerebrovascular endothelial cells, and plays an important role in the pathogenesis of atherosclerosis and ischemic cerebral vascular diseases (16-19). Hypoxia results in the deficiency of energy metabolism, intracellular acidosis and increased membrane permeability, all of which lead to the release of intracellular ET-1 (2). Similarly, our study revealed a higher level of ET-1 secretion in the BMECs in the hypoxic group, indicating that hypoxia can induce ET-1 secretion by BMECs. Of note, in the PD155080 group, ET-1 secretion was markedly reduced compared to the hypoxic group, suggesting that PD155080 inhibited hypoxia-induced ET-1 secretion from the BMECs.

The decrease in intracellular ET-1 and hypoxia activates the mRNA expression of ET-1, resulting in the increased synthesis of ET-1 (20). In our study, ET-1 mRNA levels in the hypoxic group were higher than those in the normal controls, and the ET-1 mRNA level in the PD155080 group was significantly reduced compared to that in the hypoxic group, indicating that PD155080 inhibits hypoxia-induced ET-1 gene overexpres- 

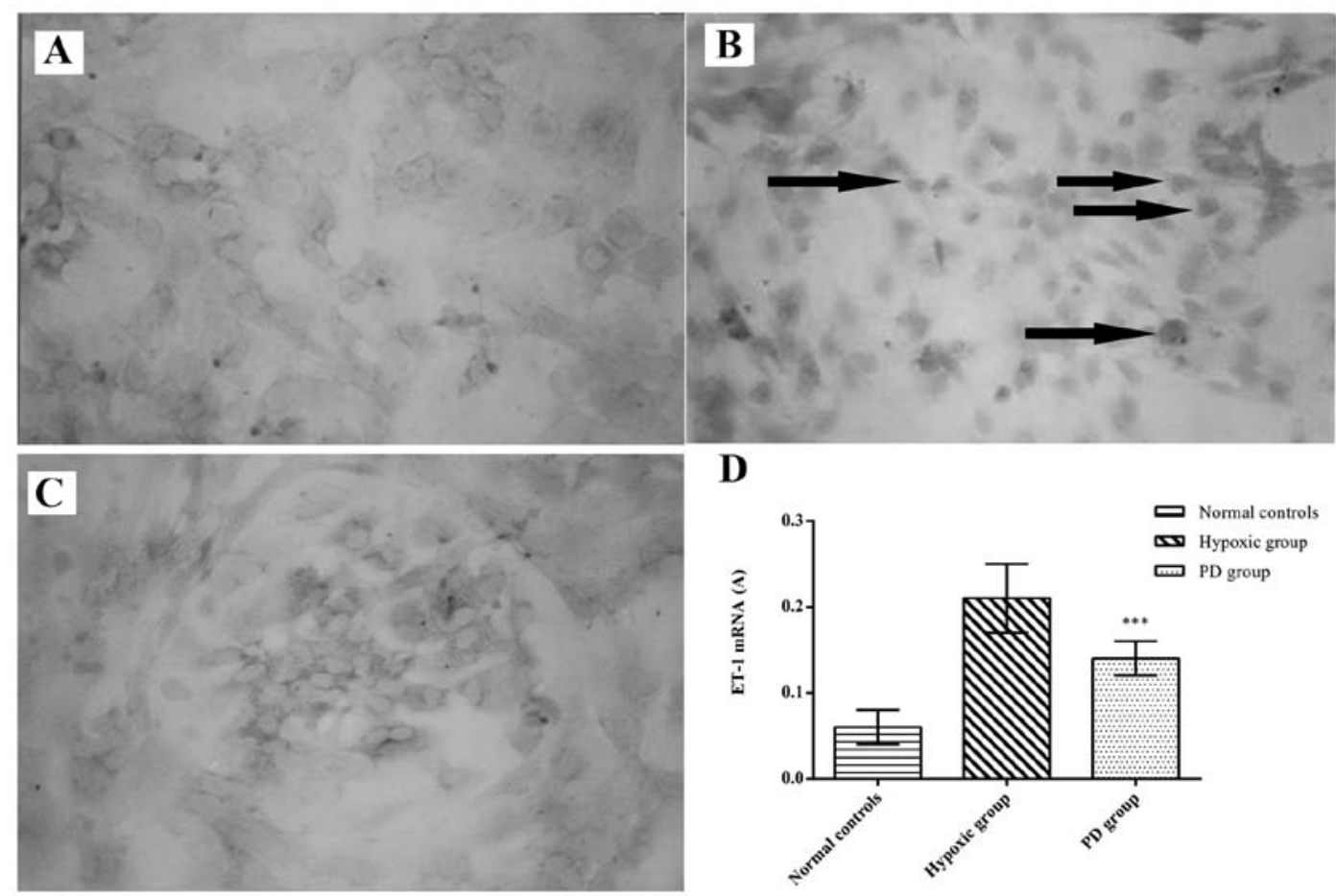

Figure 7. Effect of PD155080 on endothelin-1 (ET-1) mRNA expression in brain microvascular endothelial cells (BMECs) measured by in situ hybridization. (A) Normal controls: expression of ET-1 mRNA in BMECs. (B) Expression of ET-1 mRNA in BMECs cultured under hypoxic conditions (indicated by the arrows). (C) Expression of ET-1 mRNA in BMECs cultured with PD155080 (magnification, x200). (D) Comparison of expression of ET-1 mRNA expression in BMECs in the 3 groups. (A and C) Only weak staining was observed. (D) ET-1 mRNA expression was calculated as the mean \pm SD, ${ }^{* * *} \mathrm{P}<0.01 \mathrm{vs}$. hypoxic group; $\mathrm{n}=6$ per group and the data shown are the average of 2 individual experiments. PD, PD155080.
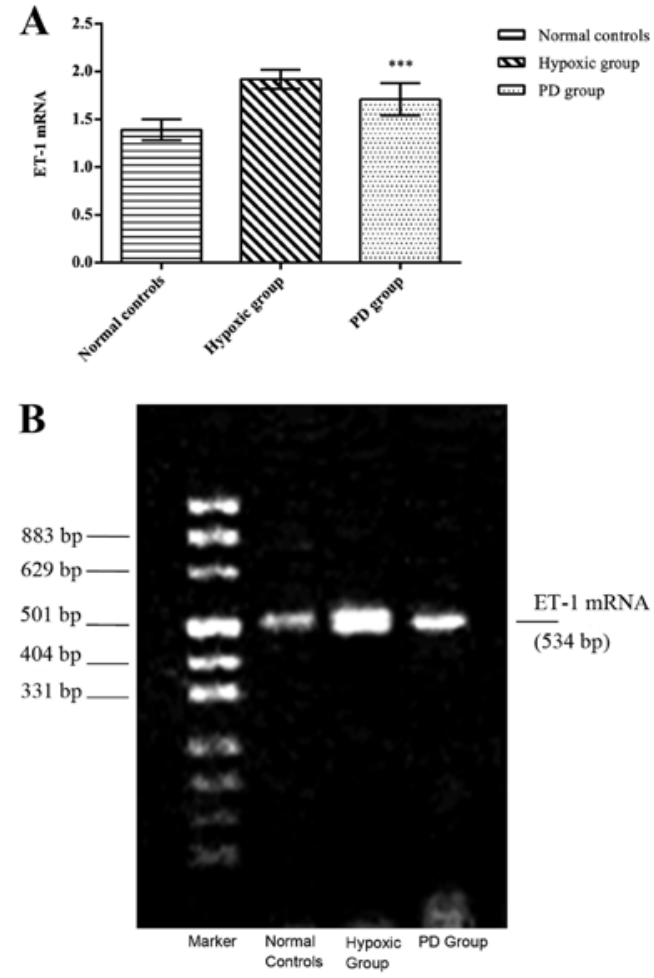

Figure 8. Effect of PD155080 on endothelin-1 (ET-1) mRNA expression in brain microvascular endothelial cells (BMECs) measured by reverse transcription PCR (RT-PCR). (A) Comparison of ET-1 mRNA expression in the BMECs in the 3 groups. (B) Agarose gel electrophoresis of the 3 groups; The ET-1 mRNA expression was calculated as the mean $\pm \mathrm{SD},{ }^{* * * *} \mathrm{P}<0.05$ vs. hypoxic group; $\mathrm{n}=6$ per group and the data shown are the average of 2 individual experiments. PD, PD155080. sion. However, the underlying mechanisms remain unclear. A previous study demonstrated that LU135252 (an ETAR antagonist) reduced the tissue concentration of ET-1, but increased the plasma levels of ET-1 in angiotensin II-treated animals, and suggested that this may be related to the displacement of ET-1 from tissues to the circulation or may be related to the direct interference of LU135252 with the production of ET in vascular tissue through its ETAR interaction (21). Another study using LU135252 suggested that ET-1 may act as an autocrine modulator of its own production in vivo through the activation of ETAR; thus, the blockade of ETAR prevented the increase in vascular ET-1 (22). It has also been reported that the binding of ET-1 to endothelin B receptor (ETBR) inhibits endothelin-converting enzyme-1 expression in endothelial cells and ETBR mediates the reuptake of ET-1 by endothelial cells (23). Therefore, the blockade of ETAR may also increase the binding of ET-1 to ETBR, which results in a reduced ET-1 level and its production. In this study, a significant decrease in ET-1 mRNA expression in the BMECs was detected in the PD155080 group compared to the hypoxic group. It is possible that PD155080 directly interferes with the production of ET-1, but it remains unclear whether this interference is related to the blockade of ETAR or to the activation of ETBR. Further studies are required to determine whether the decrease in ET-1 expression in the PD155080 group was primarily due to the effects of PD155080 directly, or due to the reduced release of intracellular ET-1.

ET-1 leads to vasoconstriction, by activating ETAR, which is expressed in endothelial cells $(6,12,24)$, indicating that the 
effects of ET-1 on BMECs are mainly mediated by ETAR. ETAR antagonists can compete against ET-1 to bind specifically to ETAR and block the biological interaction between ET-1 and ETAR. A recent study on the effects of selective ETAR antagonists in an ischemic animal model reported that ETAR antagonists appear to offer multiple neuroprotective mechanisms, including the prevention of the blood-brain barrier disruption and leukocyte infiltration (25). BQ-485, an ETAR antagonist, has been shown to prevented the oxygen saturation decrease in ischemic cerebral tissue, and increase the cerebral oxygen utilization coefficiency (26). ABT-627 and A-147627 are both ETAR antagonists that partially normalize the neurological deficits and infarct volume of MCAO mice, whilst the ETBR antagonist has no such effect $(4,27)$. In addition, rats treated with Clazosentan ${ }^{\circledR}$ (an ETAR antagonist) have shown a reduction of encephalic edema at $72 \mathrm{~h}$ and at day 7, and a decreased serum ET-1 level at $72 \mathrm{~h}$ and at day 7 (7). SB 234551 (an ETAR antagonist) protected MCAO rats by enhancing collateral blood flow and the salvage of penumbra (28). However, other studies have reported that ABT-627 had no effect on cerebral edema, infarct volume and neural function of ischemic rats (29). There are only limited in vitro studies that have reported that the effects of selective ETAR antagonists, such as BQ-123, may improve the survival of human fetal astroglial and neuronal cells upon hypoxic injury (30). To date, there are no studies on their effects on ischemic cerebral vascular endothelial cells.

PD155080 is a non-peptide specific ETAR antagonist, its oral bioavailability is $87 \%$, and it has up to 1,000 -fold selectivity for the human ETA receptor than for $\operatorname{ETBR}(8,31)$. PD155080 exerts a variety of effects on ET-1-related physiological and pathophysiological processes by blocking ETA receptors. Long-term ETAR antagonism can normalize myocardial cytosolic $\mathrm{Ca}^{2+}$ modulation, which may contribute to the anti-hypertrophic and cardioprotective effects of ETAR therapy (32). In a previous study on isolated rabbit atrial cardiomyocytes, PD155080 $(1 \mu \mathrm{M})$ was found to prevent the ET-1-induced inhibition of IK (ACh) (33). A combination of A-192621 (an ETBR antagonist) and PD155080 abolished endotoxin-induced pulmonary hypertension, enhanced cardiac performance and improved systemic oxygen delivery and acid-base balance (34). In experimental chronic renal failure rats, PD155080 reduced their high blood pressure without affecting renal function (35). Our study demonstrated that PD155080 significantly inhibited the hypoxia-induced release of ET-1 and ET-1 mRNA expression and protected BMECs from hypoxic injury. Therefore, PD155080 and other ETAR antagonists may provide therapeutic strategies for many ET-1-related diseases. Further studies on the anti-hypoxic mechanisms of PD155080 are required in order to develop novel drugs for the treatment and prevention of ischemic vascular endothelial injury.

\section{Acknowledgements}

PD155080 in this study was kindly provided by Mr. Donnie W. Ovens from Pfizer Pharmaceuticals Ltd. (New York, NY, USA). We sincerely thank Mr. Weixue Tang from the Department of Pathophysiology of Chongqing Medical University for his assistance with our study.

\section{References}

1. Shostak HDC, Lemasters JJ, Edgell CJ, et al: Role of ICE-like proteases in endothelial cell hypoxic and reperfusion injury. Biochem Biophys Res Commun 231: 844-847, 1997.

2. Luo J, Martinez J, Yin X, et al: Hypoxia induces angiogenic factors in brain microvascular endothelial cells. Microvasc Res 83: 138-145, 2012.

3. Faller DV: Endothelial cell responses to hypoxic stress. Clin Exp Pharmacol Physiol 26: 74-84, 1999.

4. Lo AC, Chen AY, Hung VK, et al: Endothelin-1 overexpression leads to further water accumulation and brain edema after middle cerebral artery occlusion via aquaporin 4 expression in astrocytic end-feet. J Cereb Blood Flow Metab 25: 998-1011, 2005.

5. Kourembanas S, Marsden PA, Mcquillan LP, et al: Hypoxia induced endothelin gene expression and secretion in cultured human endothelium. J Clin Invest 88: 1054-1060, 1991.

6. Fernandez N, Monge L, Garcia-Villalon AL, et al: Endothelin-1-induced in vitro cerebral venoconstriction is mediated by endothelin ETA receptors. Eur-J-Pharmacol 294: 483-490, 1995.

7. Moldes O, Sobrino T, Blanco M, et al: Neuroprotection afforded by antagonists of endothelin-1 receptors in experimental stroke. Neuropharmacology 63: 1279-1285, 2012.

8. Maguire JJ, Kuc RE, Doherty AM, et al: Potency of 155080, an orally active ETA receptor antagonist, determined for human endothelin receptors. J Cardiovasc Pharmacol 26 (suppl 3): S362-S364, 1995.

9. Nagy Z, Vastag M, Kolev K, et al: Human cerebral microvessel endothelial cell culture as a model system to study the blood-brain interface in ischemic/hypoxic conditions. Cell Mol Neurobiol 25: 201-210, 2005.

10. Nagy Z, Vastag M, Skopal J, et al: Human brain microvessel endothelial cell culture as a model system to study vascular factors of ischemic brain. Keio J Med 45: 200-206, 1996.

11. Wenbin, $\mathrm{Wu}$, Changlin $\mathrm{HU}$ and Weixue TANG: Microvascular endothelial cell culture of Wistar rat cerebral cortex. Journal of Chongqing Medical University 27: 151-152, 2002.

12. Martinez-Orgado J, Gonzalez R, Alonso MJ, et al: Endothelial factors and autoregulation during pressure changes in isolated newborn piglet cerebral arteries. Pediatr-Res 44: 161-167, 1998.

13. Korzeniewski $C$ and Callewaert DM: An enzyme-release assay for natural cytotoxicity. J Immunol Methods 64: 313-320, 1983.

14. Patel TR, Galbraith S, McAuley MA and McCulloch J: Endothelin-mediated vascular tone following focal cerebral ischaemia in the cat. J Cereb Blood Flow Metab 16: 679-687, 1996.

15. Goodwin AT, Smolenski RT, Gray CC, Jayakumar J, Amrani M and Yacoub MH: Role of endogenous endothelin on coronary reflow after cardioplegic arrest. J Thorac Cardiovasc Surg 122: 1167-1173, 2001.

16. Chen Y, McCarron RM, Golech S, et al: ET-1- and NO-mediated signal transduction pathway in human brain capillary endothelial cells. Am J Physiol Cell Physiol 284: C243-C249, 2003.

17. Chang CZ, Winardi D, Lin CL, et al: Attenuation of hemolysate-induced cerebrovascular endothelial cell injury and of production of endothelin-1 and big endothelin-1 by an endothelin-converting enzyme inhibitor. Surg Neurol 58: 181-187, 2002.

18. Schaller B.J: The role of endothelin in stroke: experimental data and underlying pathophysiology. Arch Med Sci 2, 146, 2006.

19. Ergul A: Endothelin-1 and diabetic complications: focus on the vasculature. Pharmacol Res 63: 477-482, 2011.

20. Yamashita K, Discher DJ, Hu J, Bishopric NH and Webster KA: Molecular regulation of the endothelin-1 gene by hypoxia. Contributions of hypoxia-inducible factor-1, activator protein-1, GATA-2, AND p300/CBP. J Biol Chem 276: 12645-12653, 2001.

21. Moreau P, d'Uscio LV, Shaw S, Takase H, Barton M, Lüscher TF: Angiotensin II increases tissue endothelin and induces vascular hypertrophy: reversal by ET(A)-receptor antagonist. Circulation 96: 1593-1597, 1997.

22. Barton M, d'Uscio LV, Shaw S, Meyer P, Moreau P, Lüscher TF: ET(A) receptor blockade prevents increased tissue endothelin-1, vascular hypertrophy, and endothelial dysfunction in salt-sensitive hypertension: Hypertension 31: 499-504, 1998.

23. Thomas F. Lüscher and Matthias Barton: Endothelins and endothelin receptor antagonists: therapeutic considerations for a novel class of cardiovascular drugs. Circulation 102: 2434-2440, 2000 . 
24. Terese PR and Nilsson GE: Endothelin induced cerebral vasoconstriction in rainbow trout, detected in a novel in vitro preparation. Neurosci Lett 325: 195-198, 2002.

25. Kaundal RK, Deshpande TA, Gulati A, et al: Targeting endothelin receptors for pharmacotherapy of ischemic stroke: current scenario and future perspectives. Drug Discov Today 17: 793-804, 2012.

26. Takasu A, Matsushima S, Takino M, et al: Effect of an endothelin-1 antagonist, BQ-485, on cerebral oxygen metabolism after complete global cerebral ischemia in dogs. Resuscitation 34 65-69, 1997.

27. Leung JW, Chung SS and Chung SK: Endothelial endothelin-1 over-expression using receptor tyrosine kinase tie-1 promoter leads to more severe vascular permeability and blood brain barrier breakdown after transient middle cerebral artery occlusion. Brain Res 1266: 121-129, 2009.

28. Legos JJ, Lenhard SC, Haimbach RE, et al: selective ET(A) receptor antagonism: perfusion/diffusion MRI used to define treatable stroke model, time to treatment and mechanism of protection. Exp Neurol 212: 53-62, 2008.

29. Khatibi NH, Lee LK, Zhou Y, et al: Endothelin receptor-A (ETa) inhibition fails to improve neonatal hypoxic-ischemic brain injury in rats. Acta Neurochir Suppl 111: 207-212, 2011.

30. Danielyan L, Mueller L, Proksch B, et al: Similar protective effects of BQ-123 and erythropoietin on survival of neural cells and generation of neurons upon hypoxic injury. Eur J Cell Biol 84: 907-913, 2005.
31. Doherty AM, Patt WC, Repine J, et al: Structure-activity relationships of a novel series of orally active nonpeptide ETA and ETA/B endothelin receptor-selective antagonists. J Cardiovasc Pharmacol 26 (suppl 3): S358-S361, 1995.

32. Friedrich B, Gerald W and Stephen H: Defective intracellular calcium handling in monocrotaline-induced right ventricular hypertrophy: protective effect of long-term endothelin-A receptor blockade with 2-benzo[1,3]dioxol-5-yl-3-benzyl-4-(4-methoxyphenyl-)-4-oxobut-2-enoate-sodium (PD 155080). J Pharmacol Exp Ther 300: 442-449, 2002.

33. Spiers JP, Kelso EJ, McDermott BJ, Scholfield CN and Silke B: Endothelin-1 mediated inhibition of the acetylcholine-activated potassium current from rabbit isolated atrial cardiomyocytes. Br J Pharmacol 119: 1427-1437, 1996.

34. Wanecek M, Oldner A, Sundin P, Alving K, Weitzberg E and Rudehill A: Effects on haemodynamics by selective endothelin $\mathrm{ET}(\mathrm{B})$ receptor and combined endothelin ET(A)/ET(B) receptor antagonism during endotoxin shock. Eur J Pharmacol 386: 235-245, 1999.

35. Potter GS, Johnson RJ and Fink GD: Role of endothelin in hypertension of experimental chronic renal failure. Hypertension 30: 1578-1584, 1997. 